\title{
Early pregnancy vitamin $D$ status and risk for adverse maternal and infant outcomes in a bi-ethnic cohort: the Behaviors Affecting Baby and You (B.A.B.Y.) Study
}

\author{
Carrie J. Nobles ${ }^{1}$, Glenn Markenson ${ }^{2}$ and Lisa Chasan-Taber ${ }^{1 *}$ \\ ${ }^{1}$ Department of Biostatistics and Epidemiology, School of Public Health $\varepsilon$ Health Sciences, Division of Biostatistics $\mathrm{E}$ \\ Epidemiology, University of Massachusetts, Amberst, MA 01003-9304, USA \\ ${ }^{2}$ Baystate Medical Center, Division of Maternal-Fetal Medicine, Springfield, MA 01199, USA \\ (Submitted 11 December 2014 - Final revision received 25 August 2015 - Accepted 9 September 2015)
}

\section{Abstract}

Vitamin D deficiency is common during pregnancy and higher in Hispanic as compared with non-Hispanic white women. However, the association between vitamin D deficiency and adverse pregnancy outcomes remains unclear and may vary across ethnic groups, in part because of genetic variation in the metabolism of vitamin D. Few studies have included Hispanic women. Therefore, we investigated this association among 237 participants in the Behaviors Affecting Baby and You Study, a randomised trial of an exercise intervention among ethnically diverse prenatal care patients in Massachusetts. Baseline serum 25-hydroxyvitamin D (25(OH)D) was measured at $15 \cdot 2$ (sD $4 \cdot 7$ ) weeks' gestation. Information on adverse pregnancy outcomes was abstracted from medical records. Mean 25(OH)D was 30.4 (sD 12.0) ng/ml; $53.2 \%$ of participants had insufficient $(<30 \mathrm{ng} / \mathrm{ml})$ and $20.7 \%$ had deficient $(<20 \mathrm{ng} / \mathrm{ml}) 25(\mathrm{OH})$ D levels. After adjusting for month of blood draw, gestational age at blood draw, gestational age at delivery, age, BMI and Hispanic ethnicity, women with insufficient and deficient vitamin D had infants with birth weights 139.74 (se 69.16) $\mathrm{g}(P=0.045)$ and 175.52 (sE 89.45) $\mathrm{g}(P=0.051)$ lower compared with women with sufficient vitamin D levels $(\geq 30 \mathrm{ng} / \mathrm{ml})$. Each $1 \mathrm{ng} / \mathrm{ml}$ increase in $25(\mathrm{OH})$ D was associated with an increased risk for gestational diabetes mellitus among Hispanic women only (relative risk 1.07; $95 \%$ CI 1.03, 1.11) in multivariable analysis. We did not observe statistically significant associations between maternal vitamin D status and other pregnancy outcomes. Our findings provide further support for an adverse impact of vitamin D deficiency on birth weight in Hispanic women.

Key words: Epidemiology: Latina: Prospective cohort studies: Vitamin D: Gestational diabetes

Low levels of 25-hydroxyvitamin D (25(OH)D) during pregnancy have been proposed as a potential contributor to adverse maternal and infant outcomes, including gestational diabetes mellitus (GDM), low birth weight/small for gestational age (SGA), spontaneous preterm delivery, caesarean delivery and gestational hypertension and preeclampsia ${ }^{(1,2)}$. Among pregnant women in the USA surveyed in the National Health and Nutrition Examination Survey from 2001 to 2006, 42\% were deficient in vitamin D (defined as $<20 \mathrm{ng} / \mathrm{ml}$ ) and $36 \%$ were insufficient

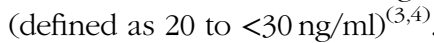

Prior observational studies of these associations have been conflicting, however, and a recent systematic review concluded that the current evidence base is insufficient to support clinical recommendations regarding vitamin D supplementation in pregnancy ${ }^{(5)}$. Specifically, in terms of adverse maternal complications, nine observational studies found that increasing $25(\mathrm{OH}) \mathrm{D}$ levels were associated with a reduced risk for
$\mathrm{GDM}^{(6-14)}$, ten found no significant association ${ }^{(15-24)}$, whereas one found that increasing $25(\mathrm{OH}) \mathrm{D}$ levels were associated with a borderline-significant increased risk for $\mathrm{GDM}^{(25)}$. Eight studies found increasing $25(\mathrm{OH}) \mathrm{D}$ levels to be associated with a lower risk for preeclampsia and gestational hypertension ${ }^{(26-33)}$, whereas six found no significant association ${ }^{(15,17,25,34-36)}$.

In terms of adverse infant outcomes, three studies found a positive association between $25(\mathrm{OH}) \mathrm{D}$ level and birth weight ${ }^{(37-39)}$, whereas four studies found no significant association $^{(23,25,40,41)}$. Similarly, seven studies have found a lower risk of delivering an SGA infant with increasing $25(\mathrm{OH}) \mathrm{D}$ levels ${ }^{(37,38,42-46)}$, whereas three studies found no significant association $^{(15,17,35)}$. Four studies found increasing $25(\mathrm{OH}) \mathrm{D}$ levels to be associated with decreased risk for preterm or spontaneous preterm delivery ${ }^{(47-50)}$, one found an increased risk $^{(25)}$, and six found no significant association ${ }^{(15,17,35,51-53)}$. Three studies found a lower risk for caesarean delivery with

Abbreviations: 25(OH)D, 25-hydroxyvitamin D; B.A.B.Y., Behaviors Affecting Baby and You; GDM, gestational diabetes mellitus; LGA, large for gestational age; $\mathrm{RR}$, relative risk; SGA, small for gestational age.

*Corresponding author: Dr L. Chasan-Taber, fax +1 413545 1645, email lct@schoolph.umass.edu 
increasing 25(OH)D levels ${ }^{(49,54,55)}$, whereas three found no significant association ${ }^{(15,25,56)}$.

The proportion of pregnant women with vitamin D deficiency and insufficiency varies by race/ethnicity ${ }^{(57)}$, with Hispanic women having higher proportions of vitamin D deficiency (45\%) compared with non-Hispanic white women $(13 \%)^{(4,58)}$. This wide variation in vitamin D deficiency levels between Hispanic and non-Hispanic white women may be due to a variety of factors including differences in the use of dietary supplements and the amount of vitamin D intake from foods. In turn, differences in the association between vitamin D and pregnancy outcomes between Hispanic and non-Hispanic whites may be due to residual confounding by social status and wealth ${ }^{(59)}$ or, in part, due to genetic variation in the metabolism of vitamin $D^{(60)}$. However, the majority of the observational studies have been limited to predominantly non-Hispanic white populations. In spite of this, several studies have found that low vitamin D increased the risk for SGA only among white women as compared with African-American women ${ }^{(37,45,46)}$; one study found that low vitamin D increased the risk for spontaneous preterm birth only among non-white women (black and Puerto Rican women combined) but not among white women ${ }^{(47)}$; and one found that deficient vitamin D increased the risk for preterm birth only among white women but not among black women ${ }^{(52)}$. However, none assessed the role of Hispanic ethnicity as an effect modifier of the relationship between vitamin D and adverse pregnancy outcomes.

Additional limitations of the prior literature include the fact that few studies have been conducted among populations at high risk for GDM, the most common treatable maternal complication of pregnancy ${ }^{(61)}$. Incidence rates of GDM are increasing in the USA and there is evidence that this increase corresponds to the rising rates of obesity and sedentary lifestyle among women of reproductive age ${ }^{(62)}$. Therefore, evaluating the potential impact of a modifiable risk factor such as vitamin D in this group has high public health significance. Finally, to our knowledge, no studies have evaluated the association between 25(OH)D level and gestational weight gain as an outcome.

Therefore, we conducted a prospective analysis utilising data from the Behaviors Affecting Baby and You (B.A.B.Y.) Study. The B.A.B.Y. Study was a randomised trial of an exercise intervention during pregnancy among ethnically diverse prenatal care patients in Western Massachusetts. We had two specific goals: (1) to investigate the association between vitamin D status in early pregnancy and the risk for subsequent adverse maternal and infant outcomes; and (2) to investigate whether these associations differed according to Hispanic ethnicity.

\section{Methods}

\section{Study design and population}

The B.A.B.Y. Study was a randomised trial assessing the effectiveness of an exercise intervention during pregnancy on reducing the risk for GDM. The B.A.B.Y. Study was conducted between 2007 and 2012 at Baystate Medical Center, a large tertiary care facility primarily serving the ethnically and socio-economically diverse communities of Springfield and
Holyoke, MA. Details regarding the B.A.B.Y. Study have been published elsewhere ${ }^{(63)}$.

The primary inclusion criterion for the B.A.B.Y. Study was being at high risk for GDM, identified as meeting one or both of the following criteria: (1) having experienced GDM in a prior pregnancy, and/or (2) having a family history of type 2 diabetes mellitus and a $\mathrm{BMI} \geq 25 \mathrm{~kg} / \mathrm{m}^{2}$. Participants were excluded if they met or exceeded the American Congress of Obstetricians and Gynecologists guidelines for physical activity $(30 \mathrm{~min}$ of moderate or vigorous activity on $\geqslant 3 \mathrm{~d} /$ week), were younger than 18 or older than 40 years of age, were at more than 20 weeks' gestation, were unable to read English at a sixthgrade level, did not plan to deliver at Baystate Medical Center, had a non-singleton pregnancy, had contraindications to engaging in moderate exercise, were currently taking medications that adversely influenced glucose tolerance, or had a personal history of diabetes outside of pregnancy, hypertension, heart disease or chronic renal disease.

A total of 252 women met the eligibility criteria for the B.A.B.Y. Study and completed a baseline assessment before randomisation. For the purposes of the current analysis, we also excluded participants who did not deliver at Baystate Medical Center ( $n$ 13) or who experienced a miscarriage or terminated pregnancy after randomisation ( $n$ 2), for a final sample size of 237. Women were included in the current analysis whether or not they were subsequently randomised. Reasons for not being randomised ( $n$ 50) included unanticipated events that occurred at the time between enrolment and randomisation, including the following: (1) contraindications to exercise noted at a subsequent prenatal medical exam ( $n$ 14; $28 \%$ ); (2) gestational age at or near the end of the second trimester at the time of randomisation ( $n 24 ; 48 \%$ ); or (3) lack of interest in continuing the study ( $n 12 ; 24 \%)$.

After a baseline assessment at which time blood was collected and covariates, including pre-pregnancy BMI, were self-reported, participants were randomised to either a 12-week exercise intervention or a comparison health and wellness intervention. Both the exercise and health and wellness interventions consisted of one face-to face meeting followed by weekly and bi-weekly mailed material and telephone booster calls.

This study was conducted according to the guidelines laid down in the Declaration of Helsinki, and all procedures involving human subjects/patients were approved by the University of Massachusetts and Baystate Medical Center Institutional Review Boards. Written informed consent was obtained from all subjects/ patients. This B.A.B.Y. Study is registered at ClinicalTrials.gov under 'An Exercise Intervention to Prevent Gestational Diabetes', under registration number NCT00728377 (https://clinicaltrials. gov/ct2/show/NCT00728377?term=chasan-taber\&rank=1).

\section{Assessment of 25-hydroxyvitamin D}

After enrolment, participants provided a fasting blood draw as part of their baseline assessment (mean 15.2 (SD 4.7) weeks' gestation). Blood draws were centrifuged, aliquoted and stored at $-80^{\circ} \mathrm{C}$. Assessment of total vitamin $\mathrm{D}\left(25(\mathrm{OH}) \mathrm{D}_{2}\right.$ and $\left.\mathrm{D}_{3}\right)$ in single aliquots was conducted by Heartland Assays, in 
Ames, IA, using DiaSorin Liaison (DiaSorin). DiaSorin Liaison has a concordance correlation coefficient of 0.95 as compared with liquid chromatography-tandem MS, which is considered to be the gold standard for assessment of total $25(\mathrm{OH}) \mathrm{D}^{(64)}$. For values $>8 \mathrm{ng} / \mathrm{ml}$, DiaSorin Liaison has $\mathrm{CV}$ for total and repeatability variation of $<10 \%{ }^{(65)}$.

Although no consensus exists for defining cutoff points for vitamin D deficiency and insufficiency most strongly associated with risk for adverse pregnancy outcomes, for the purpose of this study $25(\mathrm{OH})$ D level was categorised as deficient for levels below $20 \mathrm{ng} / \mathrm{ml}$, insufficient for levels between 20 and $<30 \mathrm{ng} / \mathrm{ml}$, and sufficient for levels at or above $30 \mathrm{ng} / \mathrm{ml}$, based on summary recommendations from $\mathrm{Holick}^{(3)}$.

\section{Assessment of adverse maternal and infant outcomes}

After delivery, data on GDM, hypertension in pregnancy and preeclampsia, infant birth weight, birth length, gestational age at birth, spontaneous preterm delivery, caesarean delivery and mother's weight at delivery were abstracted from medical records. Diagnoses were confirmed by the study obstetrician. GDM diagnosis was based upon American Diabetes Association criteria $^{(66)}$. Women were screened with a non-fasting 1-h, $50 \mathrm{~g}$ oral glucose challenge test at $24-28$ weeks' gestation. Women with glucose concentrations $>135 \mathrm{mg} / \mathrm{dl}(7.5 \mathrm{mmol} / \mathrm{l})$ were referred for a fasting 3-h, $100 \mathrm{~g}$ oral glucose tolerance test. If women exceeded two or more of the following cutoff points $95 \mathrm{mg} / \mathrm{dl}(5.3 \mathrm{mmol} / \mathrm{l})$ at fasting, $180 \mathrm{mg} / \mathrm{dl}(10.0 \mathrm{mmol} / \mathrm{l})$ at $1 \mathrm{~h}, 155 \mathrm{mg} / \mathrm{dl}(8.6 \mathrm{mmol} / \mathrm{l})$ at $2 \mathrm{~h}$ and $140 \mathrm{mg} / \mathrm{dl}(7.8 \mathrm{mmol} / \mathrm{l})$ at $3 \mathrm{~h}$ - they were diagnosed with GDM. Gestational hypertension was defined on the basis of criteria from the American College of Obstetricians and Gynecologists task force on hypertension in pregnancy, defined as two blood pressure measurements $>140 / 90 \mathrm{mmHg}$ after 20 weeks' gestation in a previously normotensive woman ${ }^{(67)}$. Preeclampsia was defined as the new onset of hypertension (blood pressure $\geq 140 / 90 \mathrm{mmHg}$ ) after 20 weeks' gestation in association with proteinuria, either $\geq 1+$ by dipstick or $\geq 300 \mathrm{mg} / 24 \mathrm{~h}$ in the absence of urinary infection ${ }^{(67)}$.

Gestational weight gain was calculated as the difference between maternal weight at delivery and pre-pregnancy weight. Total gestational weight gain was further categorised as 'inadequate', 'adequate' or 'excessive' based on prepregnancy BMI, following the Institute of Medicine criteria ${ }^{(68)}$. SGA was calculated as an infant birth weight less than the lower 10th percentile based on gestational age at birth, and large for gestational age (LGA) was calculated as an infant birth weight at or above the 90th percentile, based on estimates in the general US population by Alexander et al. ${ }^{(69)}$, which were established in a diverse, nationally representative cohort. Estimates were applied independent of infant race/ethnicity and sex as these data were unavailable. Birth weight was adjusted for gestational age, and investigated independently, and also standardised for birth length by taking the birth weight:birth length ratio.

\section{Covariate assessment}

Data on socio-demographics, medical history factors and health behaviours were obtained through self-report at entry into the study using standardised questionnaires. Socio-demographic characteristics included age, socio-economic status (household income: $\geq \$ 15000 v$. $<\$ 15000 /$ year), educational attainment (>high school $v$. $\leq$ high school), family structure (marital status: married $v$. unmarried) and number of children in a household (any children $v$. no children in household). Hispanic ethnicity (Hispanic $v$. non-Hispanic) was assessed through self-report in the manner of the US Census, the Behavioral Risk Factor Surveillance Survey, and the National Health Interview Survey. Specifically, participants were asked 'Are you Latina or of Spanish or Hispanic origin or descent? no/yes'. Medical history factors included pre-pregnancy BMI ( $<25,25$ to $<30, \geq 30 \mathrm{~kg} / \mathrm{m}^{2}$ ), parity (parous $v$. nulliparous) and personal history of GDM (yes $v$. no). Information on pre-pregnancy weight and height was abstracted from medical records.

Health behaviours include smoking $(\geq 1$ cigarette $v$. $<1$ cigarette/d), sports/exercise activity $(\geq 7.5 v$. $<7.5$ MET-h/ week) and sedentary behaviour ( $\geq 2 v,<2 \mathrm{~h} / \mathrm{d})$. The Pregnancy Physical Activity Questionnaire ${ }^{(70)}$ was used to assess sports/ exercise activity and sedentary behaviour, and asked participants to report the relative frequency with which they engaged in a variety of sports/exercise activities of light, moderate and vigorous intensity and sedentary activities. The time spent in sports/exercise activities was multiplied by the metabolic equivalent of task (MET) for each activity to derive MET-h/ week $^{(71,72)}$. Smoking during early pregnancy was assessed using a modified version of the Pregnancy Risk Assessment Monitoring System questionnaire ${ }^{(73)}$.

Additional covariates were obtained from study records and included gestational age at blood draw, month of blood draw and assigned intervention arm (exercise arm, health and wellness arm, or not randomised). Season of blood draw was calculated by dividing month of blood draw into 'winter' and 'summer'. To account for the estimated 4-8-week half-life of $25(\mathrm{OH}) \mathrm{D}$ in serum after exposure to UV radiation ${ }^{(74)}$, date cutoff points for 'summer' and 'winter' were derived by modelling the sinusoidal relationship between $25(\mathrm{OH}) \mathrm{D}$ level and month of blood draw ('1 May-31 October' for summer, winter otherwise) $)^{(75)}$.

\section{Statistical analysis}

All socio-demographic, health behaviour and medical history factors, 25(OH)D level and outcome variables were summarised as numbers and percentages for categorical variables and as means and standard deviations for continuous variables. Associations between socio-demographic, health behaviour and medical history factors with vitamin D insufficiency were estimated using unadjusted logistic regression.

Associations between 25(OH)D levels and dichotomous pregnancy outcomes (i.e. GDM, gestational hypertension, spontaneous preterm birth, SGA, LGA and caesarean delivery) were calculated using modified Poisson's regression. Associations between $25(\mathrm{OH}) \mathrm{D}$ and the multilevel pregnancy outcome of gestational weight gain were calculated using multinomial logistic regression. Associations between $25(\mathrm{OH}) \mathrm{D}$ levels and continuous pregnancy outcomes (i.e. weight gain to delivery, gestational age at delivery and birth weight, birth length, and birth weight:length ratio) were calculated using multivariable linear regression. 
Multivariable models were adjusted for potential confounding factors determined a priori by reviewing past studies and based on physiological considerations, and included month of blood draw, maternal age, pre-pregnancy BMI and Hispanic ethnicity $^{(20,46,47,54)}$. Gestational age at blood draw was also included to account for variability in $25(\mathrm{OH}) \mathrm{D}$ level due to the increase in $25(\mathrm{OH}) \mathrm{D}$ that occurs with increasing gestation ${ }^{(76)}$. Because of the particularly strong association between personal history of GDM and subsequent GDM, personal history of GDM was evaluated as a potential confounder, and included in any model in which its addition resulted in a change in effect estimate $>10 \%{ }^{(77)}$. We additionally assessed the significance of measures of socio-economic position, including household income, educational attainment and marital status. As the adjustment of these factors did not result in a change in effect estimate $>10 \%$, none were included in the final models. Models with SGA, LGA and gestational weight gain as the outcomes of interest were additionally adjusted for gestational age at delivery (weeks) to account for variability in birth weight and gestational weight gain due to length of gestation, and birth weight was adjusted for the square of gestational age. Month of blood draw was modelled as a sinusoidal function ${ }^{(75)}$.

We evaluated Hispanic ethnicity, trimester of blood draw and BMI as potential effect modifiers of the association between $25(\mathrm{OH}) \mathrm{D}$ and pregnancy outcomes by including an interaction term in the models. Because the evaluation of effect modification by Hispanic ethnicity was one of our primary aims, we present overall and ethnicity-stratified estimates for all adverse pregnancy outcomes. Study group assignment was added to all models to assess its importance as a confounder, and, as no differences in effect estimates were observed, this covariate was not retained in final multivariable models. Results of analyses were determined to be significant at $P<0 \cdot 05$. All analyses were conducted in SAS version 9.4 (SAS Institute Inc.).

Finally, we conducted several sensitivity analyses. First, we evaluated differences in baseline characteristics between participants excluded $v$. those included in the final analysis using $\chi^{2}$ or Fisher's exact tests. Second, we evaluated the impact of missing data in the GDM analysis by assigning all participants with missing outcome data as GDM cases. Finally, we evaluated the effect of controlling for mid-pregnancy BMI (approximately 20 weeks' gestation) $v$. pre-pregnancy BMI.

\section{Power}

Because the original goal of the B.A.B.Y. Study was to evaluate the effectiveness of an exercise intervention during pregnancy on reducing the risk for GDM, power for the current analysis was based on post hoc calculations. We had excellent power to detect mean differences in continuous outcomes, with $>80 \%$ power to detect differences in birth weight as small as $31.4 \mathrm{~g}$ (based on an SE of $89.2 \mathrm{~g}$ ), in total gestational weight gain of 1.23 pounds (based on an SE of 3.6 pounds) and in gestational age at delivery of 1.27 weeks (based on an SE of 0.36 weeks). In terms of dichotomous outcomes, we had $>80 \%$ power to detect OR of 0.48 or stronger magnitude for excessive gestational weight gain (based on an expected incidence rate of 0.63 ), of 0.23 or stronger magnitude for GDM (based on an expected incidence rate of $0 \cdot 14$ ), and of 0.50 or stronger magnitude for caesarean delivery (based on an expected incidence rate of 0.37 ).

\section{Results}

A total of 237 participants enrolled in the B.A.B.Y. Study were included in the analysis. This included ninety-seven participants randomised to the exercise arm (40.9\%), ninety-four participants randomised to the health and wellness arm (39.7\%) and forty-six participants who were not randomised (19.4\%). Mean gestational age at blood draw was 15.2 (SD 4.7) weeks (range 5.7, 36.7 weeks). A total of seventy-three participants had their 25 $(\mathrm{OH}) \mathrm{D}$ level assessed in the first trimester $(<13$ weeks' gestation), 160 in the second trimester ( 13 to $<26$ weeks' gestation) and four in the third trimester ( $\geq 26$ weeks' gestation). Mean level of $25(\mathrm{OH}) \mathrm{D}$ in the study population was $30 \cdot 4$ (SD $12 \cdot 0) \mathrm{ng} / \mathrm{ml}$ (range $6 \cdot 6,64.4 \mathrm{ng} / \mathrm{ml}$ ). In all, forty-nine $(20.7 \%$ ) participants had deficient levels of vitamin D $(<20 \mathrm{ng} / \mathrm{ml})$, seventy-seven $(32.5 \%)$ had insufficient levels $(20$ to $<30 \mathrm{ng} / \mathrm{ml})$ and $111(46.8 \%)$ had sufficient levels $(\geq 30 \mathrm{ng} / \mathrm{ml})$.

The study population was predominantly young $(68.8 \%$, $<30$ years), Hispanic (57.0\%) and of low income $(51.7 \%$, household incomes $<\$ 15000 /$ year) (Table 1). In terms of race, $75.6 \%$ of the participants were white and $13.5 \%$ were black. The majority of participants were overweight or obese before pregnancy $\left(94.9 \%\right.$ with $\mathrm{BMI} \geq 25 \mathrm{~kg} / \mathrm{m}^{2}$ ), parous $(70.7 \%)$ and reported $>2$ h of sedentary activity/d (52.9\%). Mean $25(\mathrm{OH}) \mathrm{D}$ level was higher among participants who were older, nonHispanic, had post-secondary education, were married and had their blood drawn at a more advanced gestational age (Table 1).

We evaluated predictors of vitamin $\mathrm{D}$ insufficiency and deficiency combined $(25(\mathrm{OH}) \mathrm{D}<30 \mathrm{ng} / \mathrm{ml}) v$. vitamin $\mathrm{D}$ sufficiency ( $\geq 30 \mathrm{ng} / \mathrm{ml}$ ) (Table 2 ), and found that each higher year of maternal age, being married, and greater than a high school education were associated with a lower odds of vitamin D insufficiency (OR 0.95; 95\% CI 0.91, 0.995, OR 0.38; $95 \%$ CI $0.21,0.70$ and OR $0.42 ; 95 \%$ CI $0.24,0.73$, respectively). Hispanic ethnicity was associated with a higher odds of vitamin D insufficiency (OR 2.53; $95 \%$ CI 1.49, 4.29). Similarly, increasing $\mathrm{kg} / \mathrm{m}^{2}$ of BMI was associated with a $5 \%$ greater odds of vitamin D insufficiency (OR 1.05; $95 \%$ 1.01, 1.10). Winter season of blood draw was associated with a 2-fold higher odds of insufficiency (OR 2.04; $95 \%$ CI 1.21, 3.44), and increasing week of gestational age at blood draw was associated with decreasing odds of insufficiency (OR 0.90; $95 \%$ CI 0.84, 0.95).

\section{Adverse maternal outcomes}

We then evaluated the association between vitamin $\mathrm{D}$ status and adverse maternal outcomes (Table 3). In all, thirty-one participants (13.7\%) were diagnosed with GDM. After adjusting for age, BMI, Hispanic ethnicity, month of blood draw and gestational age at blood draw, each $1 \mathrm{ng} / \mathrm{ml}$ increase in $25(\mathrm{OH}) \mathrm{D}$ was associated with a borderline-significant greater risk for GDM (relative risk (RR) 1.03; 95\% CI 1.00, 1.06) (Table 3).

Hispanic ethnicity was a significant effect modifier of this relationship $\left(P_{\text {interaction }}=0.02\right)$. Among Hispanic participants, 
Table 1. Characteristics of study participants; the Behaviors Affecting Baby and You Study, 2007-2012 (Numbers and percentages; mean values and standard deviations; $n 237$ )

\begin{tabular}{|c|c|c|c|c|c|c|c|c|}
\hline & \multicolumn{2}{|c|}{ Total } & \multicolumn{2}{|c|}{$\begin{array}{l}\text { Vitamin D level } \\
(\mathrm{ng} / \mathrm{ml})\end{array}$} & \multicolumn{2}{|c|}{$\begin{array}{l}\text { Vitamin D insufficiency } \\
\quad(<30 \mathrm{ng} / \mathrm{ml} ; n \text { 126) }\end{array}$} & \multicolumn{2}{|c|}{$\begin{array}{l}\text { Vitamin D sufficiency } \\
(\geq 30 \mathrm{ng} / \mathrm{ml} ; n 111)\end{array}$} \\
\hline & $n$ & $\%$ & Mean & SD & $n$ & $\%$ & $n$ & $\%$ \\
\hline \multicolumn{9}{|l|}{ Socio-demographic factors } \\
\hline \multicolumn{9}{|l|}{ Age (years) } \\
\hline $18-19$ & 28 & $11 \cdot 8$ & $28 \cdot 6$ & 8.9 & 17 & $13 \cdot 5$ & 11 & 9.9 \\
\hline $20-24$ & 84 & 35.4 & $29 \cdot 8$ & $12 \cdot 3$ & 46 & 36.5 & 38 & $34 \cdot 2$ \\
\hline $25-29$ & 51 & 21.5 & $26 \cdot 4$ & 11.0 & 34 & $27 \cdot 0$ & 17 & $15 \cdot 3$ \\
\hline $30-40$ & 74 & $31 \cdot 2$ & 34.5 & 12.5 & 29 & $23 \cdot 0$ & 45 & 40.5 \\
\hline \multicolumn{9}{|l|}{ Ethnicity } \\
\hline Hispanic & 135 & $57 \cdot 0$ & $28 \cdot 1$ & $10 \cdot 8$ & 85 & 67.5 & 50 & $45 \cdot 1$ \\
\hline Non-Hispanic & 102 & 43.0 & 33.4 & $13 \cdot 0$ & 41 & 32.5 & 61 & $55 \cdot 0$ \\
\hline \multicolumn{9}{|l|}{ Household income } \\
\hline$<\$ 15000$ & 90 & $51 \cdot 7$ & 29.5 & 11.5 & 50 & $58 \cdot 1$ & 40 & 45.5 \\
\hline$\geq \$ 15000$ & 84 & $48 \cdot 3$ & 32.9 & $12 \cdot 7$ & 36 & 41.9 & 48 & $54 \cdot 6$ \\
\hline \multicolumn{9}{|l|}{ Education } \\
\hline$\leq$ High school & 117 & $55 \cdot 2$ & $28 \cdot 3$ & 11.5 & 72 & 65.5 & 45 & $44 \cdot 1$ \\
\hline$>$ High school & 95 & 44.8 & 33.8 & $12 \cdot 2$ & 38 & $34 \cdot 6$ & 57 & 55.9 \\
\hline \multicolumn{9}{|l|}{ Marital status } \\
\hline Single/separated/divorced/widowed & 170 & $72 \cdot 7$ & 28.5 & 11.4 & 101 & $81 \cdot 5$ & 69 & $62 \cdot 7$ \\
\hline Married & 64 & $27 \cdot 4$ & 35.7 & $12 \cdot 6$ & 23 & $18 \cdot 6$ & 41 & $37 \cdot 3$ \\
\hline \multicolumn{9}{|l|}{ Children in household } \\
\hline 0 & 53 & 23.5 & 29.9 & $10 \cdot 3$ & 30 & $24 \cdot 8$ & 23 & 21.9 \\
\hline$\geq 1$ & 173 & $76 \cdot 6$ & 30.5 & $12 \cdot 7$ & 91 & $75 \cdot 2$ & 82 & $78 \cdot 1$ \\
\hline \multicolumn{9}{|l|}{ Medical history factors } \\
\hline \multicolumn{9}{|l|}{ Pre-pregnancy BMI $\left(\mathrm{kg} / \mathrm{m}^{2}\right)$} \\
\hline$<25$ & 12 & $5 \cdot 1$ & $32 \cdot 0$ & 11.6 & 5 & $4 \cdot 0$ & 7 & $6 \cdot 3$ \\
\hline 25 to $<30$ & 81 & $34 \cdot 2$ & $32 \cdot 6$ & $11 \cdot 8$ & 41 & 32.5 & 40 & $36 \cdot 0$ \\
\hline$\geq 30$ & 144 & $60 \cdot 8$ & $29 \cdot 0$ & $12 \cdot 1$ & 80 & 63.5 & 64 & $57 \cdot 7$ \\
\hline \multicolumn{9}{|l|}{ Parity } \\
\hline Nulliparous & 68 & $29 \cdot 3$ & $30 \cdot 2$ & 9.5 & 39 & 31.5 & 29 & $26 \cdot 9$ \\
\hline Parous & 164 & $70 \cdot 7$ & 30.4 & $13 \cdot 0$ & 85 & 68.6 & 79 & $73 \cdot 2$ \\
\hline \multicolumn{9}{|l|}{ Personal history of GDM } \\
\hline Yes & 26 & $11 \cdot 2$ & $32 \cdot 0$ & 11.4 & 11 & 8.9 & 15 & $13 \cdot 6$ \\
\hline No & 207 & 88.8 & $30 \cdot 1$ & $12 \cdot 1$ & 112 & $91 \cdot 1$ & 95 & $86 \cdot 4$ \\
\hline \multicolumn{9}{|l|}{ Behavioural factors } \\
\hline \multicolumn{9}{|l|}{ Smoking during pregnancy } \\
\hline Yes & 30 & $14 \cdot 7$ & 28.9 & $12 \cdot 7$ & 16 & $15 \cdot 1$ & 14 & $14 \cdot 3$ \\
\hline No & 174 & $85 \cdot 3$ & $31 \cdot 0$ & $12 \cdot 2$ & 90 & $84 \cdot 9$ & 84 & $85 \cdot 7$ \\
\hline Sports/exercise activity - baseline (M & & & & & & & & \\
\hline$<7.5$ & 135 & 64.9 & $31 \cdot 1$ & 11.9 & 66 & $61 \cdot 7$ & 69 & $68 \cdot 3$ \\
\hline$\geq 7.5$ & 73 & $35 \cdot 1$ & 30.6 & 12.4 & 41 & $38 \cdot 3$ & 32 & 31.7 \\
\hline Sedentary behaviour - baseline $(\mathrm{h} / \mathrm{d})$ & & & & & & & & \\
\hline$<2$ & 97 & $47 \cdot 1$ & $32 \cdot 2$ & $14 \cdot 0$ & 48 & $44 \cdot 4$ & 49 & $50 \cdot 0$ \\
\hline$\geq 2$ & 109 & 52.9 & $29 \cdot 4$ & $10 \cdot 2$ & 60 & $55 \cdot 6$ & 49 & $50 \cdot 0$ \\
\hline Factors related to study design & & & & & & & & \\
\hline Gestational age at blood draw (weeks & & & & & & & & \\
\hline$<12$ & 56 & 23.6 & $25 \cdot 7$ & $10 \cdot 0$ & 40 & $31 \cdot 8$ & 16 & $14 \cdot 4$ \\
\hline 12 to $<20$ & 142 & 59.9 & $30 \cdot 9$ & $12 \cdot 0$ & 74 & $58 \cdot 7$ & 68 & $61 \cdot 3$ \\
\hline$\geq 20$ & 39 & $16 \cdot 5$ & 35.4 & $12 \cdot 8$ & 12 & 9.5 & 27 & $24 \cdot 3$ \\
\hline Season of blood draw & & & & & & & & \\
\hline Summer (1 May-31 October) & 98 & 41.4 & $32 \cdot 1$ & $11 \cdot 7$ & 42 & $33 \cdot 3$ & 56 & $50 \cdot 5$ \\
\hline Winter (1 November-30 April) & 139 & $58 \cdot 7$ & $29 \cdot 2$ & $12 \cdot 2$ & 84 & $66 \cdot 7$ & 55 & $49 \cdot 6$ \\
\hline Study group assignment & & & & & & & & \\
\hline Exercise arm & 97 & $40 \cdot 9$ & $29 \cdot 7$ & 11.4 & 50 & $39 \cdot 7$ & 47 & $42 \cdot 3$ \\
\hline Health and wellness arm & 94 & $39 \cdot 7$ & $31 \cdot 0$ & $12 \cdot 3$ & 48 & $38 \cdot 1$ & 46 & $41 \cdot 4$ \\
\hline Not randomised & 46 & $19 \cdot 4$ & $30 \cdot 7$ & 12.9 & 28 & $22 \cdot 2$ & 18 & $16 \cdot 2$ \\
\hline
\end{tabular}

GDM, gestational diabetes mellitus, MET, metabolic equivalent of task.

* Numbers may not total to 237 because of missing data.

unadjusted mean vitamin D levels were $9 \mathrm{ng} / \mathrm{ml}$ lower among those who developed GDM (mean 27.1 (sD 10.5) ng/ml) as compared with those who did not develop GDM (mean $36 \cdot 2$ (sD $10 \cdot 1) \mathrm{ng} / \mathrm{ml}$ ). In multivariable models, we observed an adverse impact of $25(\mathrm{OH}) \mathrm{D}$ on risk for GDM limited to Hispanic women only ( $n$ 135) (RR 1.07; $95 \%$ CI $1.03,1.11 \mathrm{ng} / \mathrm{ml}$ ). Among non-Hispanic women ( $n$ 102), the RR was 1.00 (95\% CI $0.97,1.04)$. In addition, Hispanic women with vitamin D insufficiency had a $68 \%$ lower risk for GDM as compared with those with vitamin D insufficiency (RR 0.32; $95 \%$ CI 0.11, 0.92). 
Table 2. The association between covariates and vitamin $D$ insufficiency $v$. sufficiency $(<30 v$. $\geq 30 \mathrm{ng} / \mathrm{ml})$; the Behaviors Affecting Baby and You Study, 2007-2012 (Odds ratios and $95 \%$ confidence intervals)

\begin{tabular}{|c|c|c|}
\hline & \multicolumn{2}{|c|}{ Vitamin D insufficiency $(<30 \mathrm{v} . \geq 30 \mathrm{ng} / \mathrm{ml})$} \\
\hline & $\mathrm{OR}^{*}$ & $95 \% \mathrm{Cl}$ \\
\hline \multicolumn{3}{|l|}{ Socio-demographic factors } \\
\hline Age (years) & 0.95 & $0.91,0.995$ \\
\hline Hispanic ethnicity (yes $v$. no) & 2.53 & $1.49,4.29$ \\
\hline Household income ( $\geq \$ 15000$ v. $<\$ 15000 /$ year) & 0.60 & $0.33,1.09$ \\
\hline Education (>high school $v$. $\leq$ high school) & 0.42 & $0.24,0.73$ \\
\hline Marital status (married $v$. not married) & 0.38 & $0.21,0.70$ \\
\hline Children in household (yes $v$. no) & 0.85 & $0.46,1.58$ \\
\hline \multicolumn{3}{|l|}{ Behavioural factors } \\
\hline Smoking during pregnancy (yes $v$. no) & 1.07 & $0.49,2.32$ \\
\hline Sports/exercise activity ( $\geq 7.5 \mathrm{v} .<7.5 \mathrm{MET}$-h/week) & 1.34 & $0.76,2.37$ \\
\hline Sedentary behaviour $(\geq 2 v .<2 \mathrm{~h} / \mathrm{d})$ & 1.25 & $0.72,2.16$ \\
\hline \multicolumn{3}{|l|}{ Medical history factors } \\
\hline BMI $\left(\mathrm{kg} / \mathrm{m}^{2}\right)$ & 1.05 & $1 \cdot 01,1 \cdot 10$ \\
\hline Parity (yes v. no) & 0.80 & $0.45,1.42$ \\
\hline \multicolumn{3}{|l|}{ Factors related to timing of blood draw } \\
\hline Gestational age at blood draw (week) & 0.90 & $0.84,0.95$ \\
\hline Season (winter $v$. summer) & 2.04 & $1.21,3.44$ \\
\hline \multicolumn{3}{|l|}{ Study group assignment } \\
\hline Health and wellness arm $v$. exercise arm & 0.98 & $0.56,1.73$ \\
\hline Not randomised $v$. exercise arm & 1.46 & $0.72,2.99$ \\
\hline
\end{tabular}

Vitamin D insufficiency was not associated with GDM among non-Hispanic women.

In all, fourteen (6.3\%) participants were diagnosed with hypertension in pregnancy (inclusive of preeclampsia) and eleven ( $4.9 \%)$ were diagnosed with preeclampsia; thirty-three (16.4\%) participants had inadequate total gestational weight gain, and $128(63.7 \%)$ had excessive total gestational weight gain (Table 3). However, there were no observed associations between vitamin D status and overall hypertension in pregnancy, preeclampsia and inadequate or excessive gestational weight gain. Timing of blood draw was a statistically significant effect modifier of the relationship between vitamin D status and gestational weight gain. Among participants who had their blood drawn in the first trimester, a $1 \mathrm{ng} / \mathrm{ml}$ increase in $25(\mathrm{OH})$ $\mathrm{D}$ was associated with a $17 \%$ greater odds of having excessive gestational weight gain (OR 1.17; $95 \%$ CI 1.01, 1.36). In contrast, the OR of excessive gestational weight gain for those who had their blood drawn in the second and third trimesters was 1.01 (95\% CI 0.98, 1.05).

Finally, personal history of GDM was not a significant confounder in any model. We also did not observe effect modification of the association between 25(OH)D and other adverse maternal outcomes by Hispanic ethnicity or timing of blood draw. None of the estimates stratified by Hispanic ethnicity reached significance with the exception of those for GDM risk.

\section{Adverse infant outcomes}

We then evaluated the association between vitamin D status and adverse infant outcomes (Table 4). A total of twelve women $(5.5 \%)$ experienced a spontaneous preterm birth, twenty-one women (9.6\%) gave birth to an SGA infant, thirty-one (14.2\%) to an LGA infant and eighty-three (36.9\%) experienced a caesarean delivery. After adjusting for age, BMI, Hispanic ethnicity, month of blood draw, gestational age at blood draw and gestational age at delivery, women with vitamin D deficiency had a RR of $2 \cdot 14$ (95\% CI $0 \cdot 67,6 \cdot 88$ ) for delivering an SGA infant, which was not statistically significant. We did not observe statistically significant effect modification of the relationship between vitamin $\mathrm{D}$ status and SGA by ethnicity $(P=0 \cdot 12)$. Similarly, vitamin D levels were not significantly associated with other categorical adverse infant outcomes.

Mean birth weight was 3379.67 (SD 594.48) g and mean gestational age was 39.14 (SD 1.93) weeks (range 26.9, 42.0 weeks). After adjusting for age, BMI, Hispanic ethnicity, month of blood draw, gestational age at blood draw and the square of gestational age at delivery, women who had insufficient vitamin D levels $(<30 \mathrm{ng} / \mathrm{ml})$ or deficient vitamin D levels $(<20 \mathrm{ng} / \mathrm{ml}$ ) had infants with birth weights 139.74 (SE 69.16) g $(P=0.045)$ and 175.52 (sE 89.45) $\mathrm{g}(P=0.051)$ lower compared with women with sufficient vitamin D levels $(\geq 30 \mathrm{ng} / \mathrm{ml})$ (Table 4). Lastly, there was no statistically significant effect modification of this relationship by BMI $(P=0 \cdot 31)$.

Levels of $25(\mathrm{OH}) \mathrm{D}$ were not statistically significantly associated with gestational age at delivery, birth length or birth weight/ length. Finally, no effect modification of any of the associations between $25(\mathrm{OH}) \mathrm{D}$ and infant outcomes was observed by Hispanic ethnicity or timing of blood draw. None of the estimates stratified by Hispanic ethnicity reached statistical significance.

\section{Sensitivity analyses}

There were no statistically significant differences between women who were excluded from the analysis (e.g. not eligible/did not 
Table 3. Multivariable* relative risks (RR) for the association between vitamin D and adverse maternal outcomes; the Behaviors Affecting Baby and You Study, $2007-2012$ (Numbers and percentages; relative risks, odds ratios and $95 \%$ confidence intervals; mean values and standard deviations; regression coefficients with their standard errors)

\begin{tabular}{|c|c|c|c|c|c|c|c|c|c|c|c|c|c|c|}
\hline \multirow[b]{2}{*}{ Maternal outcomes } & \multicolumn{2}{|c|}{ Cases } & \multicolumn{4}{|c|}{ Vitamin D continuous ( $\mathrm{ng} / \mathrm{ml})$} & \multicolumn{4}{|c|}{ Vitamin D insufficiency $(<30 \mathrm{v} . \geq 30 \mathrm{ng} / \mathrm{ml})$} & \multicolumn{4}{|c|}{ Vitamin D deficiency $(<20 \mathrm{v} . \geq 30 \mathrm{ng} / \mathrm{ml}) \dagger$} \\
\hline & $n$ & $\%$ & $\mathrm{RR}$ & & $95 \% \mathrm{Cl}$ & $P$ & $\mathrm{RR}$ & & $95 \% \mathrm{Cl}$ & $P$ & $\mathrm{RR}$ & & $95 \% \mathrm{Cl}$ & $P$ \\
\hline Gestational diabetes mellitus (total group) & 31 & 13.7 & 1.03 & & $1.00,1.06$ & 0.08 & 0.80 & & $0.36,1.77$ & 0.57 & 0.37 & & $0.10,1.43$ & 0.15 \\
\hline Hispanic $\neq$ & 14 & $10 \cdot 7$ & 1.07 & & $1.03,1.11$ & 0.001 & 0.32 & & $0.11,0.92$ & 0.03 & & & & \\
\hline Non-Hispanic $\ddagger$ & 17 & 17.7 & 1.00 & & $0.97,1.04$ & 0.85 & 1.91 & & $0.77,4.72$ & 0.16 & & & & \\
\hline Hypertension in pregnancy & 14 & $6 \cdot 3$ & 0.98 & & $0.93,1.03$ & 0.48 & 1.31 & & $0.42,4.12$ & 0.65 & 1.41 & & $0.30,6.64$ & 0.66 \\
\hline Hispanic & 8 & 6.1 & 0.97 & & $0.89,1.06$ & 0.48 & 1.22 & & $0.26,5 \cdot 60$ & 0.80 & & & & \\
\hline Non-Hispanic & 6 & 6.5 & 0.99 & & $0.95,1.04$ & 0.77 & 1.43 & & $0.26,7.86$ & 0.68 & & & & \\
\hline Preeclampsia & 11 & 4.9 & 0.97 & & $0.91,1.03$ & 0.26 & 2.05 & & $0.55,7.64$ & 0.29 & $2 \cdot 81$ & & $0.52,15 \cdot 34$ & 0.23 \\
\hline Hispanic & 6 & 4.6 & 0.95 & & $0.85,1.06$ & 0.36 & 1.75 & & $0.36,8.60$ & 0.49 & & & & \\
\hline \multirow[t]{2}{*}{ Non-Hispanic } & 5 & $5 \cdot 4$ & 0.98 & & $0.94,1.03$ & 0.43 & 2.42 & & $0.38,15 \cdot 46$ & 0.35 & & & & \\
\hline & $n$ & $\%$ & OR & & $95 \% \mathrm{Cl}$ & $P$ & OR & & $95 \% \mathrm{Cl}$ & $P$ & OR & & $95 \% \mathrm{Cl}$ & $P$ \\
\hline Inadequate gestational weight gain§ & 33 & $16 \cdot 4$ & 1.00 & & $0.95,1.04$ & 0.79 & 0.96 & & $0.33,2.82$ & 0.94 & 0.63 & & $0.16,2.52$ & 0.51 \\
\hline Hispanic & 21 & $17 \cdot 1$ & 1.01 & & $0.95,1.07$ & 0.83 & 0.63 & & $0.11,3.76$ & 0.61 & 0.31 & & $0.03,3.93$ & 0.37 \\
\hline Non-Hispanic & 12 & $15 \cdot 4$ & 0.98 & & $0.92,1.05$ & 0.62 & 1.24 & & $0.31,4.90$ & 0.76 & 0.91 & & $0.17,5.02$ & 0.91 \\
\hline Excessive gestational weight gain§ & 128 & 63.7 & 1.00 & & $0.96,1.03$ & 0.93 & 0.88 & & $0.29,2 \cdot 01$ & 0.77 & 0.62 & & $0.22,1.71$ & 0.35 \\
\hline Hispanic & 78 & 63.4 & 0.98 & & $0.95,1.04$ & 0.74 & 1.11 & & $0.30,4.07$ & 0.88 & 0.84 & & $0.17,4.26$ & 0.83 \\
\hline \multirow[t]{2}{*}{ Non-Hispanic } & 50 & $64 \cdot 1$ & 1.00 & & $0.96,1.05$ & 0.87 & 0.40 & & $0 \cdot 28,2 \cdot 15$ & 0.62 & 0.51 & & $0 \cdot 15,1 \cdot 79$ & 0.29 \\
\hline & Mean & SD & $B$ & $\mathrm{SE}$ & $95 \% \mathrm{Cl}$ & $P$ & $B$ & SE & $95 \% \mathrm{Cl}$ & $P$ & B & SE & $95 \% \mathrm{Cl}$ & $P$ \\
\hline Weight gain to delivery (kg) & 29.0 & $20 \cdot 7$ & 0.01 & 0.13 & $-0.24,0.26$ & 0.94 & $2 \cdot 57$ & 2.98 & $-3 \cdot 30,8 \cdot 44$ & 0.39 & -2.85 & 3.80 & $-10 \cdot 34,4 \cdot 64$ & 0.45 \\
\hline
\end{tabular}

* Multivariable modified Poisson's, multinomial logistic and linear regression models were adjusted for month of blood draw as a sinusoidal function, gestational age at blood draw (weeks), age (years), pre-pregnancy BMI (kg/ $\mathrm{m}^{2}$ ) and Hispanic ethnicity (yes $v$. no). Inadequate gestational weight gain, excessive gestational weight gain and weight gain to delivery were additionally adjusted for gestational age at delivery (weeks).

$\dagger$ The small number of cases precluded calculation of estimates for vitamin $D$ deficiency $v$. sufficiency.

Sultinomil logistic regression used to model the mullievel outcome of indequate, adquate and $\mathrm{D}$ 
Table 4. Multivariable* relative risks (RR) for the association between vitamin D and adverse infant outcomes; the Behaviors Affecting Baby and You Study, 2007-2012 (Numbers and percentages; relative risks and $95 \%$ confidence intervals; mean values and standard deviations; $\beta$ coefficients with their standard errors)

\begin{tabular}{|c|c|c|c|c|c|c|c|c|c|c|c|c|c|c|}
\hline \multirow[b]{2}{*}{ Infant outcomes } & \multicolumn{2}{|c|}{ Cases } & \multicolumn{4}{|c|}{ Vitamin D continuous ( $\mathrm{ng} / \mathrm{ml})$} & \multicolumn{4}{|c|}{ Vitamin D insufficiency $(<30 \mathrm{v} . \geq 30 \mathrm{ng} / \mathrm{ml})$} & \multicolumn{4}{|c|}{ Vitamin D deficiency $(<20 \mathrm{v} . \geq 30 \mathrm{ng} / \mathrm{ml})$} \\
\hline & $n$ & $\%$ & $\mathrm{RR}$ & & $95 \% \mathrm{Cl}$ & $P$ & $\mathrm{RR}$ & & $95 \% \mathrm{Cl}$ & $P$ & $\mathrm{RR}$ & & $95 \% \mathrm{Cl}$ & $P$ \\
\hline Spontaneous preterm delivery & 12 & 5.5 & 1.01 & & $0.96,1.07$ & 0.59 & 0.95 & & $0.28,3.16$ & 0.93 & 0.87 & & $0.17,4.57$ & 0.87 \\
\hline Hispanic & 8 & $6 \cdot 3$ & 1.00 & & $0.94,1.07$ & 0.90 & 0.68 & & $0.19,2.47$ & 0.56 & 0.54 & & $0.06,4.66$ & 0.58 \\
\hline Non-Hispanic & 4 & 4.4 & 1.03 & & $0.91,1.16$ & 0.64 & 0.83 & & $0.23,14.80$ & 0.57 & 1.77 & & $0.13,23.85$ & 0.67 \\
\hline Small for gestational age & 21 & 9.6 & 0.98 & & $0.94,1.03$ & 0.44 & 1.85 & & $0.70,4.90$ & 0.21 & $2 \cdot 14$ & & $0.67,6.88$ & 0.20 \\
\hline Hispanic & 12 & 9.4 & 0.96 & & $0.90,1.02$ & 0.17 & 3.39 & & $0.69,16.59$ & 0.13 & 4.70 & & $0.86,25.85$ & 0.08 \\
\hline Non-Hispanic & 9 & $10 \cdot 0$ & 1.01 & & $0.95,1.07$ & 0.86 & 1.05 & & $0.29,3.84$ & 0.94 & 0.64 & & $0.08,5.13$ & 0.67 \\
\hline Large for gestational age & 31 & 14.2 & 1.01 & & $0.98,1.04$ & 0.48 & 0.91 & & $0.46,1.77$ & 0.77 & 0.88 & & $0.38,1.92$ & 0.71 \\
\hline Hispanic & 16 & $12 \cdot 5$ & 0.99 & & $0.95,1.03$ & 0.66 & 1.11 & & $0.43,2.89$ & 0.82 & 1.02 & & $0.32,3.21$ & 0.98 \\
\hline Non-Hispanic & 15 & $16 \cdot 7$ & 1.03 & & $0.98,1.07$ & 0.23 & 0.73 & & $0.25,2 \cdot 15$ & 0.56 & 0.74 & & $0.21,2.59$ & 0.63 \\
\hline Caesarean delivery & 83 & $36 \cdot 9$ & 1.00 & & $0.99,1.02$ & 0.64 & 1.02 & & $0.71,1.48$ & 0.91 & 1.04 & & $0.64,1.69$ & 0.88 \\
\hline Hispanic & 45 & 34.4 & 0.99 & & $0.97,1.02$ & 0.60 & 1.12 & & $0.67,1.88$ & 0.66 & $1 \cdot 11$ & & $0.56,2 \cdot 16$ & 0.76 \\
\hline \multirow[t]{2}{*}{ Non-Hispanic } & 38 & $40 \cdot 4$ & 1.01 & & $0.99,1.03$ & 0.28 & 0.91 & & $0.53,1.56$ & 0.74 & 0.98 & & $0.49,1.97$ & 0.96 \\
\hline & Mean & SD & $\beta$ & SE & $95 \% \mathrm{Cl}$ & $P$ & $\beta$ & SE & $95 \% \mathrm{Cl}$ & $P$ & $\beta$ & SE & $95 \% \mathrm{Cl}$ & $P$ \\
\hline Gestational age at delivery (weeks) & 39.14 & 1.93 & -0.01 & 0.01 & $-0.04,0.01$ & 0.32 & 0.07 & 0.28 & $-0.48,0.62$ & 0.80 & 0.09 & 0.36 & $-0.62,0.80$ & 0.81 \\
\hline Birth weight (g) & 3379.67 & 594.48 & 4.72 & 2.95 & $-1 \cdot 10,10.53$ & 0.11 & -139.74 & 69.16 & $-276.08,-3.41$ & 0.045 & -175.52 & 89.45 & $-351.86,0.83$ & 0.051 \\
\hline Birth length (cm) & $20 \cdot 20$ & 1.15 & -0.003 & 0.007 & $-0.017,0.011$ & 0.70 & -0.21 & 0.16 & $-0.54,0.11$ & 0.20 & -0.03 & 0.21 & $-0.44,0.39$ & 0.89 \\
\hline Birth weight/length $(\mathrm{g} / \mathrm{cm})$ & $170 \cdot 15$ & 20.08 & 0.19 & 0.12 & $-0.05,0.43$ & 0.12 & -5.35 & 2.85 & $-10.97,0.27$ & 0.06 & -5.90 & 3.67 & $-13 \cdot 14,1 \cdot 34$ & 0.11 \\
\hline
\end{tabular}

LGA, large for gestational age; SGA, small for gestational age

* Multivariable modified Poisson's and linear regression models were adjusted for month of blood draw as a sinusoidal function, gestational age at blood draw (weeks), age (years), pre-pregnancy BMI ( $\mathrm{kg} / \mathrm{m}^{2}$ ) and Hispanic ethnicity (yes v. no). SGA, LGA, birth weight, birth length and birth weight/length were additionally adjusted for gestational age at delivery (weeks). 
complete a baseline assessment) as compared with women who were included in terms of socio-demographic, behavioural or medical history factors, with the exception of a personal history of GDM. Women who were excluded were more likely to have a personal history of GDM as compared with those who were included (19.4 v. 11.9\%, respectively). However, when we compared women with data on GDM with women missing data on GDM, the prevalence of a personal history of GDM did not differ significantly between these groups (12.0 v. $13.3 \%$, respectively). When we assigned all participants missing GDM as GDM cases, we found no meaningful differences in effect estimates.

Finally, pre-pregnancy BMI did not appear to substantially modify the observed relationships. Specifically, estimates from a sensitivity analysis adjusting for mid-pregnancy BMI (approximately 20 weeks gestation) in lieu of pre-pregnancy BMI were virtually unchanged.

\section{Discussion}

In this prospective study of early-pregnancy maternal vitamin $\mathrm{D}$ status and risk of adverse maternal and infant outcomes in an ethnically diverse population at high risk for GDM, we found that women with insufficient or deficient vitamin D had infants with lower birth weights than did women with sufficient levels, after adjustment for age, Hispanic ethnicity, pre-pregnancy BMI, month of blood draw, gestational age at blood draw and gestational age at delivery. Among Hispanic women only, increasing serum vitamin D level in early pregnancy was associated with a small increased risk for GDM. We did not observe statistically significant associations between maternal vitamin D status and risk for gestational hypertension, SGA, LGA, spontaneous preterm birth, caesarean delivery or gestational weight gain overall, nor within strata of ethnicity.

In this ethnically diverse sample ( $57 \cdot 0 \%$ Hispanic) at high risk for GDM and other pregnancy complications, approximately half of the participants had insufficient levels of vitamin D, with one-fifth having deficient levels of vitamin D. These findings are comparable to prior studies that have included a high proportion of Hispanic participants ${ }^{(27,54,55)}$. In a study by Scholl et $a l .{ }^{(54)}$ in New Jersey, which included $54.1 \%$ Hispanic women, the authors found a $34.7 \%$ prevalence of vitamin D deficiency $(<50 \mathrm{nmol} / \mathrm{l})$. In a study by Merewood et al. $^{(55)}$ in Boston, Massachusetts, which included 52.9\% Hispanic women, the authors found that $22.6 \%$ of participants had vitamin D levels $<37.5 \mathrm{nmol} / 1$. In a study by Baker et al. ${ }^{(27)}$ in Chapel Hill, North Carolina, which included $26 \%$ Hispanic women, the authors found a $33.6 \%$ prevalence of vitamin D insufficiency, with $12.4 \%$ of participants being vitamin D deficient.

Our study population had a mean BMI of $32 \cdot 8(\mathrm{sD} 6 \cdot 3) \mathrm{kg} / \mathrm{m}^{2}$ and included a high percentage of participants who were overweight $\left(34.2 \% \mathrm{BMI} \geq 25\right.$ and $\left.<30 \mathrm{~kg} / \mathrm{m}^{2}\right)$ or obese $(60.8 \%$ BMI $\geq 30 \mathrm{~kg} / \mathrm{m}^{2}$ ) before pregnancy. The majority of prior studies were limited to participants who were of normal weight and/or overweight, with mean BMI ranging from $20^{(25)}$ to $30.5 \mathrm{~kg} / \mathrm{m}^{2(27)}$. However, our findings for the prevalence of vitamin D deficiency and insufficiency were similar to, or somewhat lower than, those of studies that included higher proportions of obese participants. For example, a study by Baker et $a l .{ }^{(27)}$ in Chapel Hill, North Carolina, in which participants had a mean BMI of $30(95 \%$ CI 28,35$) \mathrm{kg} / \mathrm{m}^{2}$ for preeclampsia cases and $31(95 \%$ CI 27,35$) \mathrm{kg} / \mathrm{m}^{2}$ for controls, found $46 \%$ of participants to be vitamin D deficient or insufficient as compared with $20.7 \%$ for vitamin D deficiency and $32.5 \%$ for insufficiency in our study. In a study by Gernand et $a l^{(42)}$ on 792 participants from twelve medical centres throughout the USA, which included $44.0 \%$ of participants who were obese and $23.4 \%$ who were overweight, the authors found a $36.6 \%$ prevalence of vitamin D deficiency, with $31.3 \%$ being vitamin $\mathrm{D}$ insufficient. Finally, our study population did not exercise for $\geq 3 \mathrm{~d} /$ week, which is comparable to national surveillance data, which found that the prevalence of meeting recommendations of physical activity during pregnancy (at least $150 \mathrm{~min} /$ week of aerobic exercise) was only $22 \cdot 9 \%{ }^{(78)}$.

Consistent with prior studies ${ }^{(79-81)}$, we found that older age, non-Hispanic ethnicity, higher education, being married and increasing gestational age were associated with lower odds of vitamin $\mathrm{D}$ insufficiency, whereas winter season and each 1-unit $\mathrm{kg} / \mathrm{m}^{2}$ increase in BMI was associated with increased odds of vitamin D insufficiency.

Our finding that early-pregnancy vitamin D insufficiency and deficiency was significantly associated with a lower birth weight (of approximately 140-180 g) is consistent with prior studies on this topic ${ }^{(37-39)}$. For example, in a prospective cohort study of 3730 women in the Netherlands, Leffelaar et al. ${ }^{(38)}$ found that participants with vitamin D levels in early pregnancy of $<12 \mathrm{ng} / \mathrm{ml}$ had a mean birth weight that was 114 (95\% CI 77.6, 151.2) g lower than those with vitamin D levels $\geq 20 \mathrm{ng} / \mathrm{ml}$. Vitamin D may help to regulate fetal growth via its role in increasing Ca transport across the placenta, as well as by the action of vitamin D on its receptors present in tissues throughout the body, which play important roles in regulating glucose metabolism ${ }^{(38)}$.

Although the majority of studies have suggested that increasing levels of vitamin $\mathrm{D}$ are either protective against the development of $\mathrm{GDM}^{(6-14)}$ or have no effect on $\mathrm{GDM}^{(15-24)}$, our findings suggest an adverse impact of higher early-pregnancy vitamin D level on risk for GDM among Hispanic women. The only previous study to report an increased risk for GDM with increasing vitamin D level was a prospective cohort among 1953 women conducted by Zhou et al. ${ }^{(25)}$ in southern China. The authors similarly found that each increasing $\mathrm{ng} / \mathrm{ml}$ of $25(\mathrm{OH}) \mathrm{D}$ was associated with a $2 \%$ higher odds of GDM (OR 1.02; $95 \%$ CI 1.001, 1.03), after adjustment for maternal age, systolic/diastolic blood pressure, pre-pregnancy BMI and serum Ca level ${ }^{(25)}$. A systematic review by Burris \& Camargo ${ }^{(82)}$ noted that, although an association between vitamin $\mathrm{D}$ insufficiency and deficiency and an increased risk for GDM has been found in several studies, many of these studies were limited by lack of control for potential covariates, such as race/ethnicity and BMI.

Differences in the impact of vitamin D on GDM by ethnicity may be due to genetic variation in the metabolism of vitamin $D$. For example, a recent study by Zheng et al. ${ }^{(83)}$ suggested that genetic variation in insulin receptor substrate 1 (IRS1) may modify the observed protective effect of vitamin $\mathrm{D}$ on type 2 
diabetes risk. Specifically, the authors found that circulating 25 $(\mathrm{OH}) \mathrm{D}$ modulated the associations of IRS1 variant $r s 2943641$ with type 2 diabetes and insulin resistance in Puerto Rican female adults. The authors concluded that this gene-nutrient interaction, which appears to be limited to women, warrants further examination in randomised controlled trials of vitamin D supplementation.

However, our study faced several limitations. Women who were included in the study were less likely to have a personal history of GDM as compared with women who were excluded. Therefore, loss to follow-up, even non-differential, may be one potential explanation for our findings for vitamin D and GDM as those lost were more likely to have a history of GDM (and presumably current GDM). In addition, given the small number of total cases, a lack of data at the lower ranges of vitamin D could be responsible, in part, for the association with continuous vitamin D. However, in a sensitivity analysis assigning all participants with missing data to GDM case status, results remained largely unchanged. In addition, the robustness of our findings was further supported by the observation that unadjusted mean vitamin D was lower among Hispanic women with GDM as compared with Hispanic women without GDM, but comparable among non-Hispanic women. In addition, it is possible that our population has unique social and economic factors related to dietary intake and sun exposure relevant to vitamin D status. Specifically, the Hispanic participants in our study were drawn from predominantly Puerto Rican and Dominican communities, who share a disproportionate burden of adverse pregnancy outcomes ${ }^{(84-86)}$ and socio-economic risk factors such as lower education, lower income, poor nutrition and lower physical activity levels ${ }^{(87-89)}$ as compared with other Hispanic groups and non-Hispanic whites. Finally, because differential weight gain during pregnancy could potentially modify our findings for vitamin D and risk for GDM, we conducted a sensitivity analysis adjusting for mid-pregnancy BMI in lieu of pre-pregnancy BMI, but our results were not meaningfully altered.

The small number of cases of several other adverse pregnancy outcomes also constrained our ability to evaluate their association with 25(OH)D. However, although the majority of CI do not provide statistically significant evidence, point estimates were consistent with previous research for outcomes such as gestational hypertension/preeclampsia ${ }^{(27-33,90)}$ and having an SGA infant ${ }^{(37,38,42-46)}$. The study was not designed to have sufficient power to investigate effect modification, and findings of lack of effect modification for the majority of study outcomes should not be construed to indicate evidence of a lack of interaction. In addition, the borderline significance of our findings for vitamin D and birth weight must be viewed in the light of multiple comparisons, where the probability of a type I error is greater.

$25(\mathrm{OH}) \mathrm{D}$ was assessed in early pregnancy using DiaSorin Liaison. Early-pregnancy serum samples were chosen as they help to establish a clear temporal association between $25(\mathrm{OH}) \mathrm{D}$ and subsequent adverse pregnancy outcomes, reducing the potential for reverse-causation inherent in cross-sectional designs. In addition, because 25(OH)D levels increase naturally during pregnancy ${ }^{(76)}$, obtaining samples during early pregnancy helps to reduce this source of inter-person variability. Comparable to prior studies ${ }^{(11,33,35)}$, we used a single aliquot, which may lead to a less precise measure than duplicate or triplicate aliquots. However, the strong association of $25(\mathrm{OH}) \mathrm{D}$ with expected predictors of $25(\mathrm{OH}) \mathrm{D}$ status, such as age, ethnicity, BMI, season and gestational age, suggests that this single measure had reasonably low variability. Indeed, Diasorin Liaison has a low $(<10 \%)$ total and repeatability $\mathrm{CV}^{(65)}$ and has been utilised in several studies investigating the association between $25(\mathrm{OH}) \mathrm{D}$ level in pregnancy and adverse pregnancy outcomes $^{(11,17,31,35)}$ Any variability in measurement of $25(\mathrm{OH}) \mathrm{D}$ is expected to be independent of the outcomes assessed in this study, and therefore would likely lead to an underestimation of the observed effect estimates. In addition, although we utilised cutoff points for $25(\mathrm{OH}) \mathrm{D}$ deficiency and insufficiency that are commonly used in research and practice for the general adult population $^{(3)}$, cutoff points for vitamin D status during pregnancy have yet to be validated. This potential misclassification of vitamin D status would also tend to bias findings towards the null for the binary categorisation of $25(\mathrm{OH}) \mathrm{D}$, and underestimate the observed effect sizes.

In summary, in this prospective study of women who were ethnically diverse and at high risk for GDM, we found that women with vitamin D deficiency and insufficiency had infants with lower birth weights as compared with women with sufficient levels of vitamin D. A significant increase in risk for GDM with increasing $\mathrm{ng} / \mathrm{ml}$ of $25(\mathrm{OH}) \mathrm{D}$ was found only among Hispanic women. This suggests that further research into the association between vitamin D and GDM among Hispanic women is needed, and highlights the need for large, wellconducted studies in diverse cohorts.

\section{Acknowledgements}

The present study was funded by National Institutes of Health (NIH)/National Institute of Diabetes and Digestive and Kidney Diseases (NIDDK) grant R01DK074876 and Collaborative Biomedical Research grant 369739-2 from Baystate Medical Center.

The author contributions are as follows: L. C.-T. conceived the topic for the manuscript. C. J. N. researched the literature, performed the statistical analysis and drafted the manuscript. L. C.-T., G. M. and C. J. N. participated in the design of the study and interpretation of study findings. G. M. confirmed cases of adverse pregnancy outcomes. All authors read and approved the final version of the manuscript.

The authors have no financial or personal conflicts of interest to declare.

\section{References}

1. Thorne-Lyman A \& Fawzi WW (2012) Vitamin D during pregnancy and maternal, neonatal and infant health outcomes: a systematic review and meta-analysis. Paediatr Perinat Epidemiol 26, Suppl. 1, 75-90.

2. Christesen HT, Falkenberg T, Lamont RF, et al. (2012) The impact of vitamin D on pregnancy: a systematic review. Acta Obstet Gynecol Scand 91, 1357-1367.

3. Holick MF (2007) Vitamin D deficiency. N Engl J Med 357 , 266-281. 
4. Ginde AA, Sullivan AF, Mansbach JM, et al. (2010) Vitamin D insufficiency in pregnant and nonpregnant women of childbearing age in the United States. Am J Obstet Gynecol 202, 436.e1-436.e8.

5. Harvey NC, Holroyd C, Ntani G, et al. (2014) Vitamin D supplementation in pregnancy: a systematic review. Health Technol Assess 18, 1-190.

6. Lacroix M, Battista MC, Doyon M, et al. (2014) Lower vitamin D levels at first trimester are associated with higher risk of developing gestational diabetes mellitus. Acta Diabetol 51, 609-616.

7. Cho GJ, Hong SC, Oh MJ, et al. (2013) Vitamin D deficiency in gestational diabetes mellitus and the role of the placenta. Am J Obstet Gynecol 209, 560.e1-560.e8.

8. Zuhur SS, Erol RS, Kuzu I, et al. (2013) The relationship between low maternal serum 25-hydroxyvitamin D levels and gestational diabetes mellitus according to the severity of 25-hydroxyvitamin D deficiency. Clinics (Sao Paulo) 68, 658-664.

9. Napartivaumnuay N, Niramitmahapanya S, Deerochanawong C, et al. (2013) Maternal 25 hydroxyvitamin D level and its correlation in Thai gestational diabetes patients. J Med Assoc Thai 96, Suppl. 3, S69-S76.

10. Wang O, Nie M, Hu YY, et al. (2012) Association between vitamin $\mathrm{D}$ insufficiency and the risk for gestational diabetes mellitus in pregnant Chinese women. Biomed Environ Sci $\mathbf{2 5}$, 399-406.

11. Parlea L, Bromberg IL, Feig DS, et al. (2011) Association between serum 25-hydroxyvitamin D in early pregnancy and risk of gestational diabetes mellitus. Diabet Med 29, e25-e32.

12. Soheilykhah S, Mojibian M, Rashidi M, et al. (2010) Maternal vitamin D status in gestational diabetes mellitus. Nutr Clin Pract 25, 524-527.

13. Zhang C, Qiu C, Hu FB, et al. (2008) Maternal plasma 25-hydroxyvitamin D concentrations and the risk for gestational diabetes mellitus. PLOS ONE 3, e3753.

14. Maghbooli Z, Hossein-Nezhad A, Karimi F, et al. (2008) Correlation between vitamin $\mathrm{D}_{3}$ deficiency and insulin resistance in pregnancy. Diabetes Metab Res Rev 24, 27-32.

15. Fernandez-Alonso AM, Dionis-Sanchez EC, Chedraui $\mathrm{P}$, et al. (2012) First-trimester maternal serum 25-hydroxyvitamin D(3) status and pregnancy outcome. Int J Gynaecol Obstet 116, 6-9.

16. Whitelaw DC, Scally AJ, Tuffnell DJ, et al. (2014) Associations of circulating calcium and 25-hydroxyvitamin D with glucose metabolism in pregnancy: a cross-sectional study in European and South asian women. J Clin Endocrinol Metab 99, 938-946.

17. Schneuer FJ, Roberts CL, Guilbert C, et al. (2014) Effects of maternal serum 25-hydroxyvitamin $\mathrm{D}$ concentrations in the first trimester on subsequent pregnancy outcomes in an Australian population. Am J Clin Nutr 99, 287-295.

18. McLeod DS, Warner JV, Henman M, et al. (2012) Associations of serum vitamin D concentrations with obstetric glucose metabolism in a subset of the Hyperglycemia and Adverse Pregnancy Outcome (HAPO) study cohort. Diabet Med 29, e199-e204.

19. Burris HH, Rifas-Shiman SL, Kleinman K, et al. (2012) Vitamin D deficiency in pregnancy and gestational diabetes mellitus. $\mathrm{Am} \mathrm{J}$ Obstet Gynecol 207, 182.e1-182.e8.

20. Baker AM, Haeri S, Camargo CA Jr, et al. (2012) First-trimester maternal vitamin D status and risk for gestational diabetes (GDM) a nested case-control study. Diabetes Metab Res Rev 28, 164-168.

21. Savvidou MD, Akolekar R, Samaha RB, et al. (2011) Maternal serum 25-hydroxyvitamin D levels at $11(+0)-13(+6)$ weeks in pregnant women with diabetes mellitus and in those with macrosomic neonates. BJOG 118, 951-955.
22. Makgoba M, Nelson SM, Savvidou M, et al. (2011) First-trimester circulating 25-hydroxyvitamin D levels and development of gestational diabetes mellitus. Diabetes Care 34, 1091-1093.

23. Farrant HJ, Krishnaveni GV, Hill JC, et al. (2009) Vitamin D insufficiency is common in Indian mothers but is not associated with gestational diabetes or variation in newborn size. Eur J Clin Nutr 63, 646-652.

24. Clifton-Bligh RJ, McElduff P \& McElduff A (2008) Maternal vitamin $\mathrm{D}$ deficiency, ethnicity and gestational diabetes. Diabet Med 25, 678-684.

25. Zhou J, Su L, Liu M, et al. (2014) Associations between 25-hydroxyvitamin D levels and pregnancy outcomes: a prospective observational study in southern China. Eur $J$ Clin Nutr 68, 925-930.

26. Bodnar LM, Catov JM, Simhan HN, et al. (2007) Maternal vitamin D deficiency increases the risk of preeclampsia. J Clin Endocrinol Metab 92, 3517-3522.

27. Baker AM, Haeri S, Camargo CA Jr, et al. (2010) A nested case-control study of midgestation vitamin D deficiency and risk of severe preeclampsia. J Clin Endocrinol Metab 95 , 5105-5109.

28. Robinson CJ, Wagner CL, Hollis BW, et al. (2013) Association of maternal vitamin D and placenta growth factor with the diagnosis of early onset severe preeclampsia. Am J Perinatol 30, 167-172.

29. Woodham PC, Brittain JE, Baker AM, et al. (2011) Midgestation maternal serum 25-hydroxyvitamin D level and soluble fms-like tyrosine kinase 1 /placental growth factor ratio as predictors of severe preeclampsia. Hypertension 58, 1120-1125.

30. Wei SQ, Audibert F, Hidiroglou N, et al. (2012) Longitudinal vitamin $\mathrm{D}$ status in pregnancy and the risk of pre-eclampsia. BJOG 119, 832-839.

31. Wei SQ, Audibert F, Luo ZC, et al. (2013) Maternal plasma 25-hydroxyvitamin D levels, angiogenic factors, and preeclampsia. Am J Obstet Gynecol 208, 390.e1-390.e6.

32. Ullah MI, Koch CA, Tamanna S, et al. (2013) Vitamin D deficiency and the risk of preeclampsia and eclampsia in Bangladesh. Horm Metab Res 45, 682-687.

33. Xu L, Lee M, Jeyabalan A, et al. (2014) The relationship of hypovitaminosis D and IL-6 in preeclampsia. Am J Obstet Gynecol 210, 149.e1-149.e7.

34. Yu CK, Ertl R, Skyfta E, et al. (2013) Maternal serum vitamin D levels at 11-13 weeks of gestation in preeclampsia. J Hum Hypertens 27, 115-118.

35. Shand AW, Nassar N, Von Dadelszen P, et al. (2010) Maternal vitamin $\mathrm{D}$ status in pregnancy and adverse pregnancy outcomes in a group at high risk for pre-eclampsia. BJOG 117, 1593-1598.

36. Powe CE, Seely EW, Rana S, et al. (2010) First trimester vitamin $\mathrm{D}$, vitamin $\mathrm{D}$ binding protein, and subsequent preeclampsia. Hypertension 56, 758-763.

37. Gernand AD, Simhan HN, Klebanoff MA, et al. (2013) Maternal serum 25-hydroxyvitamin D and measures of newborn and placental weight in a US multicenter cohort study. J Clin Endocrinol Metab 98, 398-404.

38. Leffelaar ER, Vrijkotte TG \& van Eijsden M (2010) Maternal early pregnancy vitamin D status in relation to fetal and neonatal growth: results of the multi-ethnic Amsterdam Born Children and their Development cohort. Br J Nutr 104, 108-117.

39. Song SJ, Si S, Liu J, et al. (2013) Vitamin D status in Chinese pregnant women and their newborns in Beijing and their relationships to birth size. Public Health Nutr 16, 687-692.

40. Walsh JM, McGowan CA, Kilbane M, et al. (2013) The relationship between maternal and fetal vitamin $\mathrm{D}$, insulin resistance, and fetal growth. Reprod Sci 20, 536-541. 
41. Morley R, Carlin JB, Pasco JA, et al. (2006) Maternal 25-hydroxyvitamin D and parathyroid hormone concentrations and offspring birth size. J Clin Endocrinol Metab 91, 906-912.

42. Gernand AD, Simhan HN, Caritis S, et al. (2014) Maternal vitamin D status and small-for-gestational-age offspring in women at high risk for preeclampsia. Obstet Gynecol 123, $40-48$.

43. Burris HH, Rifas-Shiman SL, Camargo CA Jr, et al. (2012) Plasma 25-hydroxyvitamin D during pregnancy and small-forgestational age in black and white infants. Ann Epidemiol 22, 581-586.

44. van den Berg G, van Eijsden M, Vrijkotte TG, et al. (2013) Suboptimal maternal vitamin D status and low education level as determinants of small-for-gestational-age birth weight. Eur J Nutr 52, 273-279.

45. Ertl R, Yu CK, Samaha R, et al. (2012) Maternal serum vitamin D at 11-13 weeks in pregnancies delivering small for gestational age neonates. Fetal Diagn Ther 31, 103-108.

46. Bodnar LM, Catov JM, Zmuda JM, et al. (2010) Maternal serum 25-hydroxyvitamin D concentrations are associated with small-for-gestational age births in white women. J Nutr $\mathbf{1 4 0}$, 999-1006.

47. Bodnar LM, Klebanoff MA, Gernand AD, et al. (2014) Maternal vitamin D status and spontaneous preterm birth by placental histology in the US Collaborative Perinatal Project. $\mathrm{Am} \mathrm{J}$ Epidemiol 179, 168-176.

48. Thota C, Menon R, Fortunato SJ, et al. (2014) 1,25-Dihydroxyvitamin $\mathrm{D}$ deficiency is associated with preterm birth in African American and Caucasian women. Reprod Sci 21, 244-250.

49. Perez-Ferre N, Torrejon MJ, Fuentes M, et al. (2012) Association of low serum 25-hydroxyvitamin D levels in pregnancy with glucose homeostasis and obstetric and newborn outcomes. Endocr Pract 18, 676-684.

50. Shibata M, Suzuki A, Sekiya T, et al. (2011) High prevalence of hypovitaminosis D in pregnant Japanese women with threatened premature delivery. J Bone Miner Metab 29, 615-620.

51. Thorp JM, Camargo CA, McGee PL, et al. (2012) Vitamin D status and recurrent preterm birth: a nested case-control study in high-risk women. BJOG 119, 1617-1623.

52. Dunlop AL, Taylor RN, Tangpricha V, et al. (2012) Maternal micronutrient status and preterm versus term birth for black and white US women. Reprod Sci 19, 939-948.

53. Baker AM, Haeri S, Camargo CA Jr, et al. (2011) A nested case-control study of first-trimester maternal vitamin D status and risk for spontaneous preterm birth. Am J Perinatol 28, 667-672.

54. Scholl TO, Chen X \& Stein P (2012) Maternal vitamin D status and delivery by cesarean. Nutrients $\mathbf{4}, 319-330$.

55. Merewood A, Mehta SD, Chen TC, et al. (2009) Association between vitamin D deficiency and primary cesarean section. J Clin Endocrinol Metab 94, 940-945.

56. Savvidou MD, Makgoba M, Castro PT, et al. (2012) Firsttrimester maternal serum vitamin $\mathrm{D}$ and mode of delivery. $\mathrm{BrJ}$ Nutr 108, 1972-1975.

57. Bodnar LM \& Simhan HN (2010) Vitamin D may be a link to black-white disparities in adverse birth outcomes. Obstet Gynecol Surv 65, 273-284.

58. Collins-Fulea C, Klima K \& Wegienka GR (2012) Prevalence of low vitamin $\mathrm{D}$ levels in an urban midwestern obstetric practice. J Midwifery Womens Health 57, 439-444.

59. Kaufman JS, Cooper RS \& McGee DL (1997) Socioeconomic status and health in blacks and whites: the problem of residual confounding and the resiliency of race. Epidemiology $\mathbf{8}$, 621-628.
60. Robinson-Cohen C, Hoofnagle AN, Ix JH, et al. (2013) Racial differences in the association of serum 25-hydroxyvitamin D concentration with coronary heart disease events. JAMA $\mathbf{3 1 0}$, 179-188.

61. International Association of Diabetes and Pregnancy Study Groups Consensus Panel, Metzger BE, Gabbe SG, et al. (2010) International association of diabetes and pregnancy study groups recommendations on the diagnosis and classification of hyperglycemia in pregnancy. Diabetes Care 33, 676-682

62. Committee on Practice Bulletins - Obstetrics (2013) Practice Bulletin No. 137: gestational diabetes mellitus. Obstet Gynecol 122, Pt 1, 406-416.

63. Chasan-Taber L, Marcus BH, Stanek E, et al. (2009) A randomized controlled trial of prenatal physical activity to prevent gestational diabetes: design and methods. $J$ Womens Health (Larchmt) 18, 851-859.

64. Farrell CJ, Martin S, McWhinney B, et al. (2012) State-of-the-art vitamin D assays: a comparison of automated immunoassays with liquid chromatography-tandem mass spectrometry methods. Clin Chem 58, 531-542.

65. Hsu SA, Soldo J \& Gupta M (2013) Evaluation of two automated immunoassays for 25-OH vitamin $\mathrm{D}$ : comparison against LC-MS/MS. J Steroid Biochem Mol Biol 136, 139-145.

66. American Diabetes Association (2003) Gestational diabetes mellitus. Diabetes Care 25, Suppl. 1, S103-S105.

67. American College of Obstetricians and Gynecologists Committee on Practice Bulletins - Obstetrics (2002) ACOG practice bulletin. Diagnosis and management of preeclampsia and eclampsia. Number 33, January 2002. Obstet Gynecol 99, $159-167$.

68. Institute of Medicine and National Research Council (2009) Weight Gain During Pregnancy: Reexamining the Guidelines. Washington, DC: National Academies Press.

69. Alexander GR, Kogan MD \& Himes JH (1999) 1994-1996 US singleton birth weight percentiles for gestational age by race, Hispanic origin, and gender. Matern Child Health J 3, 225-231.

70. Chasan-Taber L, Schmidt MD, Roberts DE, et al. (2004) Development and validation of a Pregnancy Physical Activity Questionnaire. Med Sci Sports Exerc 36, 1750-1760.

71. Ainsworth BE, Haskell WL, Herrmann SD, et al. (2011) 2011 Compendium of physical activities: a second update of codes and MET values. Med Sci Sports Exerc 43, 1575-1581.

72. Ainsworth BE, Haskell WL, Leon AS, et al. (1993) Compendium of physical activities: classification of energy costs of human physical activities. Med Sci Sports Exerc 25, 71-80.

73. Tong VT, Dietz PM, Morrow B, et al. (2013) Trends in smoking before, during, and after pregnancy - Pregnancy Risk Assessment Monitoring System, United States, 40 sites, 2000-2010. MMWR Surveill Summ 62, 1-19.

74. Barrett H \& McElduff A (2010) Vitamin D and pregnancy: an old problem revisited. Best Pract Res Clin Endocrinol Metab 24, 527-539

75. Stolwijk AM, Straatman H \& Zielhuis GA (1999) Studying seasonality by using sine and cosine functions in regression analysis. J Epidemiol Community Health 53, 235-238.

76. Liu NQ \& Hewison M (2012) Vitamin D, the placenta and pregnancy. Arch Biochem Biophys 523, 37-47.

77. Mickey RM \& Greenland S (1989) The impact of confounder selection criteria on effect estimation. Am J Epidemiol 129, 125-137.

78. Evenson KR \& Wen F (2010) National trends in self-reported physical activity and sedentary behaviors among pregnant women: NHANES 1999-2006. Prev Med 50, 123-128. 
79. Bjorn Jensen C, Thorne-Lyman AL, Vadgard Hansen L et al. (2013) Development and validation of a vitamin D status prediction model in Danish pregnant women: a study of the Danish National Birth Cohort. PLOS ONE 8, e53059.

80. Reddy GS, Norman AW, Willis DM, et al. (1983) Regulation of vitamin $\mathrm{D}$ metabolism in normal human pregnancy. $J$ Clin Endocrinol Metab 56, 363-370.

81. Seki K, Makimura N, Mitsui C, et al. (1991) Calcium-regulating hormones and osteocalcin levels during pregnancy: a longitudinal study. Am J Obstet Gynecol 164, Pt 1, 1248-1252.

82. Burris HH \& Camargo CA Jr (2014) Vitamin D and gestational diabetes mellitus. Curr Diab Rep 14, 451.

83. Zheng JS, Parnell LD, Smith CE, et al. (2014) Circulating 25-hydroxyvitamin D, IRS1 variant rs2943641, and insulin resistance: replication of a gene-nutrient interaction in 4 populations of different ancestries. Clin Chem 60, 186-196.

84. Matthews TJ \& MacDorman MF (2013) Infant mortality statistics from the 2010 period linked birth/infant death data set. Natl Vital Stat Rep 62, 1-26.
85. MacDorman MF (2011) Race and ethnic disparities in fetal mortality, preterm birth, and infant mortality in the United States: an overview. Semin Perinatol 35, 200-208.

86. Cohen BB, Friedman DJ, Mahan CM, et al. (1993) Ethnicity, maternal risk, and birth weight among Hispanics in Massachusetts, 1987-89. Public Health Rep 108, 363-371.

87. Evenson KR, Savitz DA \& Huston SL (2004) Leisure-time physical activity among pregnant women in the US. Paediatr Perinat Epidemiol 18, 400-407.

88. Hajat A, Lucas JB \& Kington R (2000) Health outcomes among Hispanic subgroups: data from the National Health Interview Survey, 1992-95. Adv Data 310, 1-14.

89. Himmelgreen DA, Bretnall A, Perez-Escamilla R, et al. (2005) Birthplace, length of time in the US, and language are associated with diet among inner-city Puerto Rican women keywords. Ecol Food Nutr 44, 105-122.

90. Bodnar LM, Simhan HN, Powers RW, et al. (2007) High prevalence of vitamin D insufficiency in black and white pregnant women residing in the northern United States and their neonates. J Nutr 137, 447-452. 